\title{
Dynamic changes of live/apoptotic circulating tumour cells as predictive marker of response to Sunitinib in metastatic renal
}

\section{cancer}

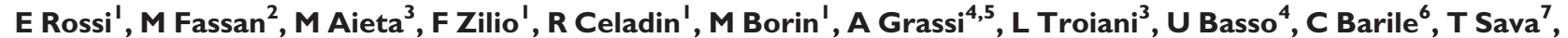 \\ C Lanza $^{2}$, L Miatello ${ }^{4}$, A Jirillo ${ }^{4}$, M Rugge $^{2}$, S Indraccolo ${ }^{4}, M$ Cristofanilli ${ }^{8}$, A Amadori ${ }^{1,4}$ and R Zamarchi*,4 \\ 'Department of Surgery, Oncology and Gastroenterology, Oncology Section, University of Padova, Padova, Italy; ${ }^{2}$ Department of Medical Diagnostic \\ Sciences \& Special Therapies, Surgical Pathology \& Cytopathology Unit, University of Padova, Padova, Italy; ${ }^{3}$ IRCCS-CROB, Rionero in Vulture (PZ), Italy; \\ ${ }^{4}$ IOV-IRCCS, via Gattamelata, 64, 35128 Padova, Italy; ${ }^{5}$ Metabolic Unit, ISIB-CNR, Padova, Italy; ${ }^{6}$ U.O.C Oncology - Ospedale 'Santa Maria della \\ Misericordia', Rovigo, Italy; ${ }^{7}$ Department of Medical Oncology, University of Verona, Verona, Italy; ${ }^{8}$ Department of Medical Oncology, Fox Chase Cancer \\ Center, Philadelphia, PA, USA
}

BACKGROUND: Recently, we developed an apoptotic assay for expanding the monitoring capabilities of the circulating tumour cells (CTC) test during therapy. An automated platform for computing CTCs was integrated with a mAb (M30) targeting a neoepitope disclosed by caspase cleavage at cytokeratin 18 in early apoptosis; we showed that live CTCs were associated with progression, consistent with enhanced cell migration and invasion. The test was first applied here to mRCC.

METHODS: Live/apoptotic CTCs changes were measured in mRCC patients receiving first-line Sunitinib and compared with circulating endothelial cell (CEC) levels.

RESULTS: The presence of EPCAM-positive, live CTCs predicts progression in individual mRCC patient, being associated with distant metastasis under first-line Sunitinib. Synchronous detection of CTCs and CEC levels discloses for the first time an association between their dynamic changes and outcome: a rapid increase of the CEC number as early as the first cycle of therapy is associated with CTC decrease in non-progressed patients, whereas a delayed response of CECs is related to higher CTC values in the progressed group indicating treatment failure.

CONCLUSION: We demonstrated that a delayed response to antiangiogenic treatment indicated by persistent detection of CECs correlates with persistent live CTCs and more aggressive disease.

British Journal of Cancer (2012) I 07, 1286-1294. doi:I0.1038/bjc.2012.388 www.bjcancer.com

Published online 6 September 2012

(c) 2012 Cancer Research UK

Keywords: renal cancer; circulating tumour cells (CTC); circulating endothelial cells (CEC); M30; sunitinib

The treatment of metastatic renal cell carcinoma (RCC) has changed employing the multitarget receptor tyrosine kinase (RTK) inhibitors with antiangiogenic properties (McDermott et al, 2005; Ratain et al, 2006; Motzer et al, 2007; Hutson et al, 2010), including Sunitinib, that inhibit cell signalling (including all receptors for PDGF and VEGF) leading to reduced tumour vascularisation, cancer cell death, and tumour shrinkage. The role of antiendothelial effects $v s$ antitumour cells targeting in vivo is a matter of debate (Xin et al, 2009; Huang et al, 2010) regardless, no predictive markers are currently available for mRCC patients treated with this class of agents.

Circulating endothelial cell (CEC) levels were recently reported to be a pharmacodynamic biomarker of antiangiogenic treatment in combination with chemotherapy for metastatic breast cancer (MBC) (Bidard et al, 2010), but validation studies are required to further define CEC threshold for poor outcome.

*Correspondence: Dr R Zamarchi; E-mail: rita.zamarchi@unipd.it Received II June 2012; revised 31 July 2012; accepted 3 August 2012; published online 6 September 2012
Inverse correlation between circulating tumour cells (CTC) burden and overall survival in solid tumours has been reported (Cristofanilli et al, 2004; Danila et al, 2007; Sastre et al, 2008); variations in CTC count indicate a significant change in prognosis as early as the first treatment cycle (Budd et al, 2006; Hayes et al, 2006; Riethdorf et al, 2007). Notwithstanding that 4 to $10 \%$ of RCC patients showed tumour thrombus in the inferior vena cava (Marshall et al, 1988), the occurrence of CTC was rarely investigated in these patients for correlation with an advanced tumour stage or more aggressive tumour phenotype (Blumke et al, 2005).

Recently, we have developed a CTC assay integrated for M30 neoepitope expression to monitor changes in the balance between live and apoptotic CTCs (Rossi et al, 2010) during treatment. This assay may be used as pharmacodynamic parameter disclosing an active disease, as documented by consistent radiological findings in MBC patients under chemotherapy (Rossi et al, 2010). As the antiangiogenic properties of recently approved RTKs in RCC would interfere with extravasation/circulation of CTCs (Bidard et al, 2010), we evaluated total and apoptotic CTC changes and their correlation with radiological response in a study evaluating first-line 
Sunitinib-treated mRCC patients. A prospective observational study was designed on the basis of the discontinuous schedule of Sunitinib administration, to monitor CTC and CEC changes during treatment intervals, when tumour evasion may occur.

\section{PATIENTS AND METHODS}

This article has been written in accordance with the REporting of tumour MARKer studies criteria (McShane et al, 2005).

\section{Study design}

We conducted a prospective, observational study to demonstrate the association between serial total and M30-positive CTC results with disease progression in patients starting a first-line Sunitinib regimen for mRCC (Pilot Study 'Metastatic renal cancer: CTC determination in first-line Sunitinib-treated patients (CTC/Sun)', IOV-IRCCS, Padova (Italy)); details of the study (inclusion and exclusion criteria, blood draw calendar) are on-line provided as Supplementary Data. Furthermore, we were interested in correlating the CTC detection with EpCAM expression in primary or metastatic tissue. Patient confidentiality was maintained per the policies and procedures of the IOV-IRCCS for protection from research risks. Study sponsors did not have access to the data.

\section{Patients}

Between June 2008 and September 2010 peripheral blood was drawn from 53 consecutive mRCC patients (12 women and 41 men, aged 26-90 years). Whole blood was also drawn from healthy control subjects (7 women and 10 men, aged 25-76 years) who neither had known illness at the time of sampling nor history of malignant disease. All enrolled patients and healthy subjects gave their informed consent for study inclusion and were enrolled using institutional review board-approved protocols.

Forty-four patients had given their consensus to undergo multiple CTC tests for the correlation between CTC changes and treatment response; one patient lacked paired CTC results notwithstanding he had initial CTC assessments and subsequent clinical and/or radiographic documentation of disease status, so he was excluded in the analysis.

After baseline evaluation, the treating physicians conducted reevaluations of the disease status based on Response Evaluation Criteria in Solid Tumour.

\section{Total and M30-positive CTC and CEC count}

Enumeration of CTCs and CECs in whole blood was performed by the CellSearch System according to manufacturer's instructions (Cristofanilli et al, 2004; Rowand et al, 2007). An event is classified as a CTC or CEC when its morphological features are consistent with that of a cell and it exhibits the phenotype EpCAM +, CK +, DAPI + and CD45- or CD146+, CD105+, DAPI + and CD45-, respectively. Quantitative results were expressed as per $7.5 \mathrm{ml}$ blood and per $4 \mathrm{ml}$ blood for CTC and CEC, respectively.

To investigate drug-induced cell death throughout Sunitinib treatment, live and apoptotic CTCs were detected by integrating CTC assay with anti-M30 mAb, targeting a neoepitope disclosed by caspase cleavage at cytokeratin 18 in early apoptosis (Rossi et al, 2010); results are expressed as the total number of CTC and M30positive CTC per $7.5 \mathrm{ml}$ of blood.

\section{Immunohistochemistry (IHC)}

All enrolled patients who have undergone kidney surgery (radical nephrectomy or nephron-sparing surgery) or metastasis biopsy were included in the IHC study (34 patients) for EpCAM expression. The EpCAM expression in renal cancer is a critical issue, being reported between 15 and $40 \%$ of clear cell RCC samples depending on the study (Seligson et al, 2004; Went et al, 2005; Liu et al, 2007). Details on immunostaining and controls are on-line provided as Supplementary Data. Only positive membranous immunostaining with anti-EpCAM (clone MOC-31; Cell Marque, Rocklin, CA, USA) was considered and semiquantitatively scored in a four-tier scale that combined intensity (score-0, score-1, score-2 and score-3) and prevalence (\%) of positive immunostaining. Results were grouped as following: negative $=$ no stain; weak $=$ score -1 in $<60 \%$, or score -2 in $<30 \%$ of tumour cells; moderate $=$ score- 1 in $\geqslant 60 \%$, or score- 2 in 30 $80 \%$, or score- 3 in $<30 \%$ of tumour cells; strong $=$ score -2 in $\geqslant 80 \%$, or score- 3 in $\geqslant 30 \%$ of tumour cells (no 'strong' cases were faced in the present series).

\section{Statistical analysis}

Data were analyzed utilising the StatGraphics software (version 2.6), as previously reported (Amadori et al, 1995). The nonparametric Mann-Whitney or Wilcoxon tests were used to compare the quantitative variables. Frequencies were compared by Fisher' exact test (two tails) or $\chi^{2}$ test with Yates' correction where appropriate. Non-linear regression analysis was performed to assess the relationship between CTC and CEC levels.

The cumulative changes of live and apoptotic CTCs were expressed as previously described (Rossi et al, 2010) by the parameter $\triangle \mathrm{AUC}$ : the detected numbers of M30-negative and M30positive CTCs were separately plotted in relation to time and the area under the curve (AUC) of longitudinal graphs was calculated (by the trapezoidal rule) following a procedure which is commonly adopted to evaluate cumulative changes of serological tumour markers (de Haas et al, 2008). The difference between live and apoptotic CTC concentration-time area was calculated in all patients according to the following formula:

$$
\triangle \mathrm{AUC}={ }^{\mathrm{M} 30 \text { negative CTC }} \mathrm{AUC}-{ }^{\mathrm{M} 30 \text { positive }{ }^{\mathrm{CTC}} \mathrm{AUC} .}
$$

Progression-free survival (PFS) was measured as the time between the baseline CTC assessment (i.e., the initiation of treatment) and the documentation of first radiographic disease progression or death. Patients who were alive and progression-free at the time of analysis were censored by using the time between the baseline CTC assessment and their most recent follow-up evaluations.

The PFS between groups defined by $\leqslant 0$ or $>0 \Delta$ AUC was compared with the Kaplan-Meier method, and differences were tested with the log-rank test.

\section{RESULTS}

\section{CTC were detectable in the majority of mRCC patients}

To test whether total and M30-positive CTC were detectable in mRCC patients, blood samples from 53 patients were tested at diagnosis before starting the therapy. The patient characteristics and the distribution of CTC number are shown in Table 1. Histology was obtained in 44 patients (83\%): clear cell histotype was predominant (36 patients, $81.8 \%$ ), following papillary-cell (3 patients, $6.8 \%)$, sarcomatoid type (2 patients, $4.5 \%)$ and other histotypes (3 patients, $6.8 \%$ ).

Thirty-one $(58.5 \%)$ mRCC patients had at least one CTC, $19(35.8 \%)$ patients had two or more CTCs. Twenty-six (83.9\%) CTCs-positive patients had one or more M30-positive CTCs. The number of CTCs and M30-positive CTCs ranged from 1 to 141 (median 2) and 0 to 67 (median 2) cells, respectively. The percentage of CTC-positive patients and total CTCs resembles the data previously reported at diagnosis in other metastatic tumours such as prostate (78\% CTC-positive pts, median 9 cells) (Danila et al, 2007), breast (65\% CTC-positive patients, median 3 cells) 
Table I Patients and primary tumour characteristics by CTC and M30-positive CTC detection at baseline

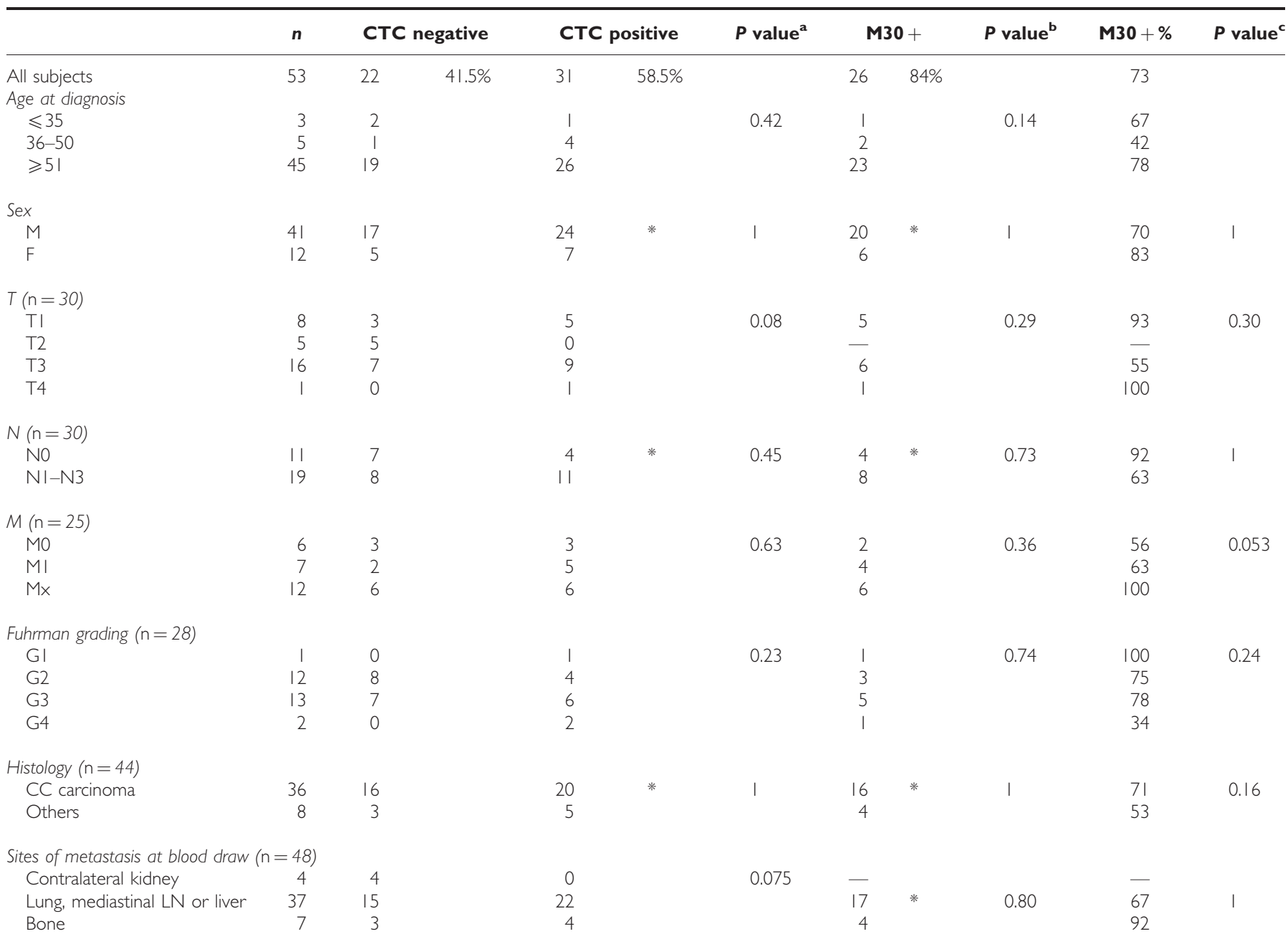

Distribution of CTC and M30-positive CTC in RCC patients at baseline

\begin{tabular}{|c|c|c|c|c|c|c|c|}
\hline CTC no. $/ 7.5 \mathrm{ml}$ & $<1$ & $\geqslant 1$ & $\geqslant 2$ & $\geqslant 3$ & $\geqslant 4$ & $\geqslant 5$ & $\geqslant 10$ \\
\hline No. of patients & 22 & 31 & 19 & 14 & 8 & 5 & 2 \\
\hline M30-positive no. $/ 7.5 \mathrm{ml}$ & $<1$ & $\geqslant 1$ & $\geqslant 2$ & $\geqslant 3$ & $\geqslant 4$ & $\geqslant 5$ & $\geqslant 10$ \\
\hline No. of patients & 5 & 26 & 16 & 10 & 6 & 4 & I \\
\hline
\end{tabular}

Abbreviations: $C T C=$ circulating tumour cells; $L N=$ lymph node; $R C C=$ renal cell carcinoma. ${ }^{a} C T C$ detection; $\chi^{2}$ test or Fisher's exact $(*)$ test were employed where

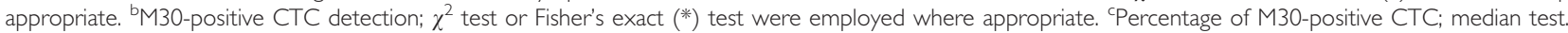

(Cristofanilli et al, 2004; Krishnamurthy et al, 2010; Sandri et al, 2010; Pierga et al, 2012) and colorectal cancer (47\% CTC-positive patients, median 5 cells of those patients with $\geqslant 2$ CTCs) (Allard et al, 2004; Sastre et al, 2008). The presence of CTCs and M30-positive CTCs at diagnosis was not associated with any specific clinicopathologic features with few exceptions (Table 1). The presence of CTCs at baseline demonstrated a trend with the detection of distant metastasis (lung, mediastinal LN, liver or bone, $P=0.075$; Table 1 ).

\section{EpCAM expression can be acquired during disease progression}

To detect CTC in follow-up study, obvious advantages of good sensitivity and reproducibility are offered by the automated technologies (Amadori et al, 2009), that mostly depend on the presence of EpCAM on the cell surface for capturing CTCs. To address this question in mRCC, histological sections were analyzed by IHC for EpCAM expression in 34 patients (64\%) that had undergone kidney surgery, either primary tumour resection (17 cases) and metastasis biopsy (6 cases (3 lung, 1 bone, 1 SNC and 1 thyroid metastasis)) or both (11 cases). Appropriate positive, negative and inner controls are shown in Supplementary Figure S1, in Supplementary data. The data obtained by IHC was compared with CTC count.

Overall, 14 out of 34 patients (41.2\%) expressed EpCAM in primary tumour, in metastasis or in both sites. As shown in Figure $1 \mathrm{~A}$, overall only minor changes were found in metastasis sections both as percentage of EpCAM-positive samples (from 32\% to $41 \%$ of analyzed samples in primary vs secondary lesions, respectively, $P=0.749$ ) and as staining intensity (moderate grade expression from $33 \%$ to $43 \%$ of EpCAM-positive samples in primary $v s$ secondary lesions, respectively, $P=1$ ). Conversely, higher percentage of EpCAM-positive samples was found by 
CellSearch analysis $(P<0.001)$ : the great majority $(85 \%)$ of the patients, which entered the IHC study, were CTC-positive, with 'zenith' (i.e. the highest CTC no./7.5 ml during follow-up) values of CTCs comprised between 1 and $4(69 \%)$, between 5 and $10(17 \%)$ and more than $10(14 \%)$.

In particular, for 11 patients CTC detection was performed at the time of metastasis biopsy, so that comparison can be performed by synchronous CTC detection and EpCAM expression in secondary lesions $v s$ EpCAM expression in primary tumours (Figure 1B-D). Synchronous CTC and IHC analysis were performed before starting the treatment. As shown in Table 2 the EpCAM-positive cases in the primary lesion ( 3 patients, weak expression) duplicate in secondary lesions (6 patients, 4 weak and 2 moderate expression; $P=0.156$ ). Remarkably, four of these six patients were negative in the primary tumour, suggesting de novo acquisition of EpCAM expression in metastasis (Figure 1B-D and Supplementary Figure S2). In seven of the seven patients (100\%) that showed EpCAM-positive IHC (in primary or secondary lesions) at least one point during follow-up CTCs were also detected (Table 2, 'zenith' CTC no.). Moreover, CTCs were further detected in three out of four patients $(75 \%)$ that appeared EpCAM-negative both in primary and secondary lesions (two patients with lung and one with SNC metastasis); in these patients at the time of the synchronous CTCs detection bone metastasis (patient number 8 and 27 in Table 2) or multiple visceral metastasis (patient number 31 in Table 2) were also documented by imaging that were not included in IHC study. Overall, higher number of EpCAM-positive samples was found by CellSearch analysis $(P=0.035)$.

\section{Serial M30-integrated CTC assay during antiangiogenic treatment}

To investigate whether the integrated test may predict therapeutic response in $\mathrm{mRCC}$, CTC and M30-positive CTC were sequentially assessed under first-line Sunitinib treatment in 43 evaluable patients.

All patients had received the therapy schedule ' $4-2$ ' with a starting dose of $50 \mathrm{mg}$ per day for 4 weeks, followed by a 2 -week off-drug period. Sunitinib-dose reduction of $25 \%(37.5 \mathrm{mg})$ and $50 \%(25 \mathrm{mg})$ for grade $3-4$ hematologic and non-hematologic toxicities was observed in $21(48.8 \%)$ and 4 patients $(9.3 \%)$, respectively.

Figure I EpCAM expression in mRCC primary tumours, metastasis and CTC. (A) EpCAM expression was analysed by $I H C$ in primary tumours $(T, n=28)$ and metastasis $(M, n=17)$ obtained from 34 patients, for comparing IHC data with CTC results. The white bars represent the EpCAM-negative $\mathrm{HC}$ in $\mathrm{T}(19$ out of 28 ) and in $\mathrm{M}$ ( 10 out of 17$)$ and patients that were CTC-negative by CellSearch assay (5 out of 34). The light brown bars represent weak staining in T (6 out of 9 ) and M (4 out of 7): the dark brown bars represent Moderate staining in $T$ ( 3 out of 9 ) and M (3 out of 7). The light blue bar symbolises patients that had I-4 CTC (20 out of 29), the dark blue bar symbolises patients that had 5-I0 CTC (5 out of 29), the deep blue bar symbolises patients that had more than IO CTC (4 out of 29). (B) The EpCAM staining profile is consistent in secondary lesions and synchronous CTC detection; one representative case of 4 is shown. The primary renal lesion (patient number 58 ) does not feature any EpCAM immunostaining (Original magnification 20X). (C) Characteristic EpCAM membranous immunoreaction appears in the tumour biopsy obtained from the surrenalic metastasis (patient number 58). (Original magnification $\times 20$ ). (D) Analysis of three rare cells in baseline blood sample of patient number 58 using an Analyzer II device (Veridex, Raritan, NJ, USA). Horizontally, the photos show the same cell stained for the combination (Comp) of CK (green) and DAPI (violet); CK PE only; DAPI only; CD45 APC only; and M30 FITC only. The red squares indicate positively stained cells: events \#I and \#7 are live CTC, exhibiting strong and irregular CK staining, respectively; in the photo \#19 based on M30 staining profile (sufficient signal relative to background) the event on the right is classified as apoptotic CTC; the event on the left is a leukocyte (CD45-positive).

Overall, median follow-up was 184 days (range 28 to 861 days). One case of complete response (CR), 5 cases of partial response (PR) and 20 cases of stable disease (SD) were observed, with median PFS of 258 days (range 40-524 days). Two cases of deadof-disease (DOD) and 15 cases of progressive disease (PD) were observed, with median time-to-progression (TTP) of 112 days (range 28-861 days).

Lower baseline median number of total and M30-positive CTCs was weakly associated with the outcome of non-progressed (including $\mathrm{CR}, \mathrm{PR}$ and $\mathrm{SD}$ ) vs progressed (including DOD and PD) patient groups (0.5 CTCs and 0.0 M30 + vs 2.0 CTCs and 1.0 $\mathrm{M} 30+, P=0.069$ and 0.061 , respectively; Table 3 ). Conversely, at the end of the first cycle no significant changes were measured in total and M30-positive CTCs number in either group (Table 3).

The presence of CTCs at baseline was not associated with the outcome: 5 of 18 CTC-negative and 12 of 25 CTC-positive patients belonged to the progressed group $(P=0.219)$; however, in the CTC-positive group of patients that completed the second cycle of

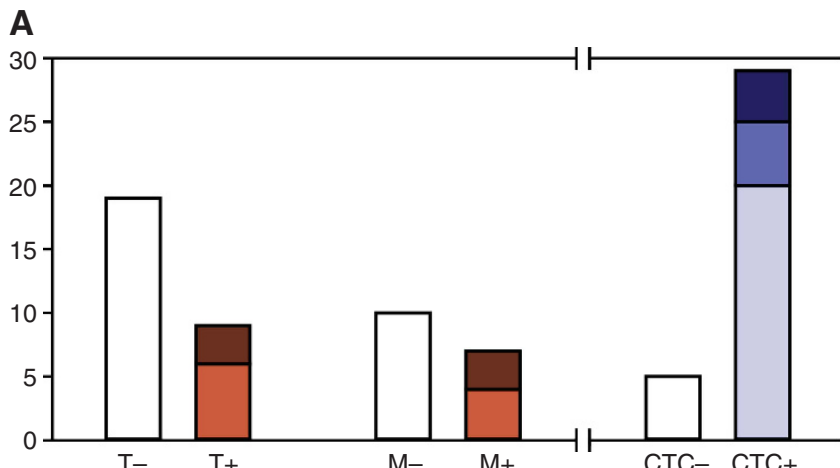

B

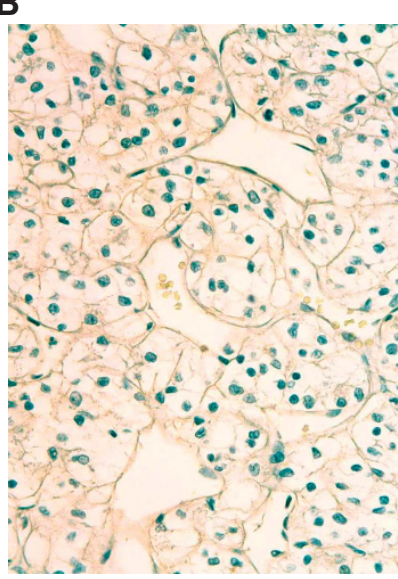

C

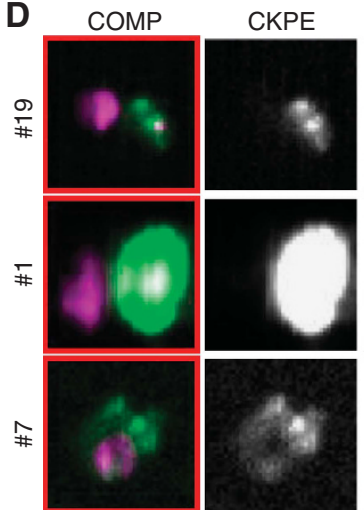

DAPI
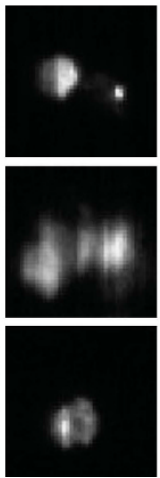

CD45 APC
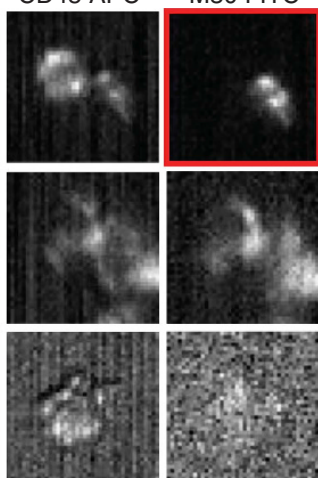
Table 2 EpCAM expression and CTC detection in $\mathrm{mRCC}$

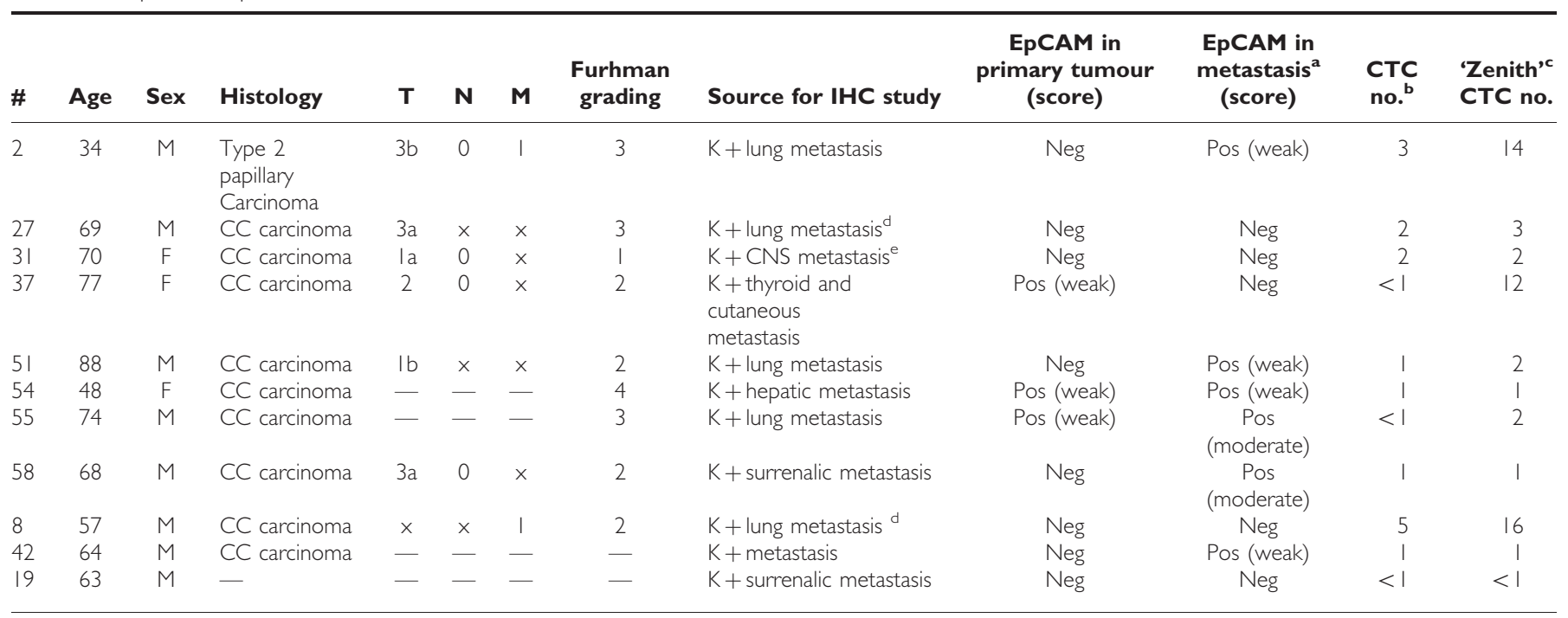

Abbreviations: $C C=$ clear cell; $C N S=$ central nervous system; $C T C=$ circulating tumour cells; $\| H C=$ immunohistochemistry; mRCC $=$ metastatic renal cell canrcinoma a Metastasis biopsy and CTC detection were synchronously performed before starting the treatment. ${ }^{b} \mathrm{CTC}$ no. $/ 7.5 \mathrm{ml}$ at the first blood draw. ${ }^{\circ}$ The highest CTC no./7.5 ml during the follow-up. ${ }^{d}$ Bone metastasis were documented by imaging that were not biopsied. ${ }^{e}$ Multiple visceral metastatic lesions were documented by imaging that were not biopsied.

Table 3 Outcome according to CTC and M30-positive CTC count and $\triangle A U C$

\begin{tabular}{|c|c|c|c|c|c|c|c|c|c|c|c|c|c|c|c|c|}
\hline & $n$ & CTC $^{a}$ & $\begin{array}{c}P \\
\text { value }^{b}\end{array}$ & $\begin{array}{l}\text { I }^{\circ} \text { Cycle } \\
\text { CTC }^{\mathrm{a}}\end{array}$ & $\begin{array}{c}P \\
\text { value }^{c}\end{array}$ & $\mathrm{M} 30+{ }^{\mathrm{d}}$ & $\begin{array}{c}P \\
\text { value }^{b}\end{array}$ & $\begin{array}{c}\mathrm{I}^{\circ} \\
\text { Cycle } \\
\mathrm{M} 30+{ }^{\mathrm{d}}\end{array}$ & $\begin{array}{c}P \\
\text { value }^{c}\end{array}$ & $\Delta A U C^{e}$ & $\begin{array}{c}P \\
\text { value }^{b}\end{array}$ & $\underset{\leqslant 0}{\Delta \mathbf{A U C}}$ & $\begin{array}{c}\Delta \mathrm{AUC} \\
>0\end{array}$ & $\begin{array}{c}P \\
\text { value }^{f}\end{array}$ & $\begin{array}{c}\text { TTP } \\
\text { (days) }^{g}\end{array}$ & $\begin{array}{c}P \\
\text { value }^{b}\end{array}$ \\
\hline \multicolumn{17}{|c|}{ Outcome according to categorised $\triangle A \cup C$} \\
\hline $\begin{array}{l}\text { Non-progressed } \\
\text { Progressed }\end{array}$ & $\begin{array}{l}26 \\
17\end{array}$ & & & & & & & & & & & $\begin{array}{l}25 \\
10\end{array}$ & $\begin{array}{l}1 \\
7\end{array}$ & 0.004 & & \\
\hline \multicolumn{17}{|c|}{ Sites of disease relapse according to $\triangle \mathrm{A} \cup \mathrm{C}$} \\
\hline $\begin{array}{l}\text { Locally } \\
\text { heightened } \\
\text { invasion }\end{array}$ & 6 & & & & & & & & & -24.00 & 0.050 & 6 & 0 & 0.017 & $|3|$ & 0.802 \\
\hline $\begin{array}{c}\text { Distant } \\
\text { metastasis }\end{array}$ & 11 & & & & & & & & & 34.50 & & 4 & 7 & & 107 & \\
\hline
\end{tabular}

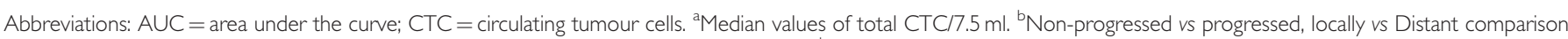
by Mann-Whitney test. 'Before and after $1^{\circ}$ cycle comparison by Wilcoxon paired test. 'Median values of M30-positive CTC/7.5 ml. " Live/apoptotic CTC balance over the

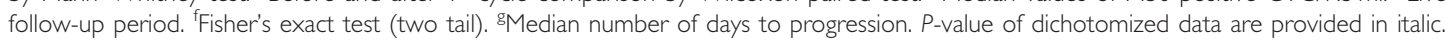

Sunitinib (21 cases), the presence of M30-negative CTCs at baseline was weakly associated with the poor outcome (6 progressed out of 7 (85.7\%) vs 6 progressed out of $14(42.9 \%)$ between live and apoptotic CTCs-positive patients, $P=0.078)$ ).

\section{Analysis of the live/apoptotic CTC cumulative changes over the follow-up period}

Accurately assessing the cumulative changes of live/apoptotic CTCs number under chemotherapy have disclosed the predictive relevance of apoptotic CTCs in MBC (Rossi et al, 2010). To address this question in mRCC the observed variations under Sunitinib were expressed as reported (Rossi et al, 2010) by the parameter $\triangle A U C$ : the detected numbers of M30-negative (live) and M30positive (apoptotic) CTCs were plotted in relation to time and the difference of the AUC of longitudinal graphs was calculated (Rossi et al, 2010).
The non-progressed group showed lower median values of $\triangle \mathrm{AUC}$ compared with the progressed $(-86.00$ vs $-5.50, P=0.010$, Table 3), indicating that higher values of extra apoptotic CTCs over the follow-up period were associated with better outcome.

Moreover, categorising the patients for positive $\triangle \mathrm{AUC}$ value (that is expression of extra live CTCs over the follow-up period) $v s$ negative or $0 \triangle \mathrm{AUC}$ (that is expression of extra apoptotic CTC over the follow-up period or equal live/apoptotic CTC), we found that a positive $\triangle \mathrm{AUC}$ was associated with progression $(P=0.004$, Table 3$)$.

To assess the goodness of the 0 cutoff for the $\triangle$ AUC, 1000 distributions of size 500 were generated for non-progressed patients using bootstrap techniques. A 95\% confidence interval (CI) was estimated for the probability of committing a first type error, that is the probability of classifying a patient as progressed (because $\triangle \mathrm{AUC}>0$ ) when actually he is not. The $95 \%$ CI was $(0 ; 92)$. Despite the small sample size of this data set, the analysis performed supports the choice of the 0 cutoff for discriminating between progressed and non-progressed patients. 


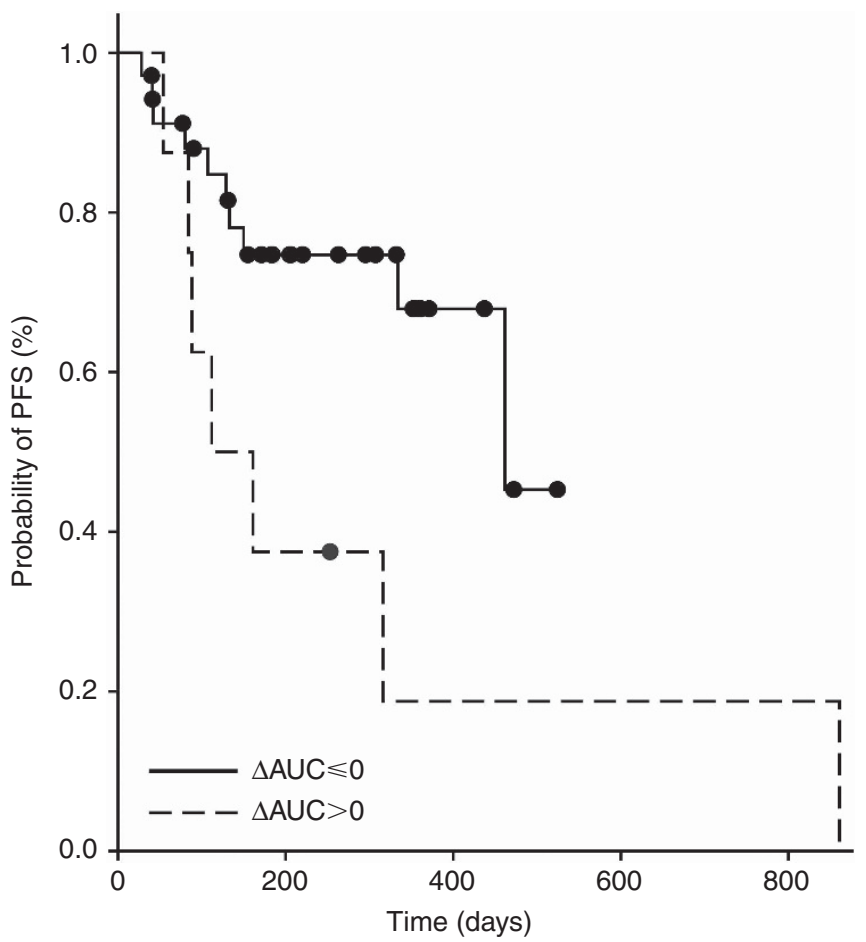

Figure 2 Progression-free survival (PFS) for patients with negative or equal 0 vs positive $\triangle A \cup C$. Progression-free survival was measured as the time between the baseline CTC assessment and documentation of first radiographic evidence of disease progression or death. The $\triangle \mathrm{AUC}$ criterion represents the difference between live and apoptotic CTC concentrationtime area and was calculated in all patients according to the following formula: $\triangle \mathrm{AUC}={ }^{\mathrm{M} 30 \text { negative } \mathrm{CTC}} \mathrm{AUC}-{ }^{\mathrm{M} 30 \text { positive } \mathrm{CTC}} \mathrm{AUC}$

Table 4 Outcome according to CEC

\begin{tabular}{lcccccc}
\hline & $\boldsymbol{n}$ & CEC $^{\mathbf{a}}$ & $\boldsymbol{P}_{\text {value }}{ }^{\mathbf{b}}$ & $\mathbf{I}^{\circ}$ Cycle CEC $^{\mathbf{a}}$ & $\boldsymbol{P}_{\text {value }}{ }^{\mathbf{b}}$ & $\boldsymbol{P}$ value \\
\hline Non-progressed & 15 & 34 & 0.867 & 63.5 & 0.751 & 0.057 \\
Progressed & 13 & 45 & & 87.0 & & 0.155
\end{tabular}

Abbreviation: $\mathrm{CEC}=$ circulating endothelial cell. a Median values of $\mathrm{CEC} / 4 \mathrm{ml}$. ${ }^{\mathrm{b}} \mathrm{Non}$ progressed vs progressed comparison by Mann-Whitney test. 'Before and after $1^{\circ}$ cycle comparison by Mann-Whitney test.

The criterion of $\triangle \mathrm{AUC}>0$ has sensitivity $42 \%$, specificity $96 \%$, positive predictive value $87 \%$ and negative predictive value $71 \%$ in predicting the patients who will undergo disease progression.

Shorter median PFS was observed for patients who had $\triangle \mathrm{AUC}$ $>0$ compared with $\triangle \Delta \mathrm{AUC} \leqslant 0$ patients (112 vs 462 days; $P=0.030$; Figure 2).

At progression, 11 of 17 progressed patients showed distant metastasis that were associated with higher median $\triangle \mathrm{AUC}$ values than in the locally recurring patients $(34.50 v s-24.00 ; P=0.050$; Table 3); categorising the progressed patients for $\triangle \mathrm{AUC}>0 \mathrm{vs}$ $\triangle \mathrm{AUC} \leqslant 0$, positive $\triangle \mathrm{AUC}$ was associated with distant metastasis $(P=0.017$, Table 3$)$. Distant metastases were not associated with shorter TTP $(P=0.802)$.

\section{Synchronous CEC and CTC changes during antiangiogenic treatment}

Under antiangiogenic treatment combined with chemotherapy CTC changes were not reported as an early surrogate marker of survival (Bidard et al, 2010) whereas significant decrease in CEC levels was associated with tumour progression in MBC. To investigate this issue in mRCC, CEC and CTC levels were sequentially assessed in 30 patients under first-line Sunitinib treatment.

Comparable baseline CEC values were measured both in patients and healthy controls (39 vs $45 ; P=0.845$ ) as well as in nonprogressed and progressed patients (34 vs 45; $P=0.867$, Table 4). Conversely, at the end of the first cycle increasing CEC levels were measured that appeared weakly associated with outcome (Table 4).

To establish a combinatory model using both CTCs and CEC levels, synchronous determinations were plotted in relation to time (Figure 3). The CTC and CEC changes were associated according to waveform model of regression analysis $\left(R^{2}=0.67, P=0.05\right.$, Figure 3A). The relationship between CTC and CEC levels were stronger in the non-progressed patients $\left(R^{2}=0.90, P=0.05\right)$ than in progressed patients $\left(R^{2}=0.38, P=0.05\right.$, Figure $\left.3 C\right)$.

\section{DISCUSSION}

At present, design of clinical trials, interpretation of outcome data and finally clinical managing of mRCC patients are based on predictive models of risk including a series of prognostic factors (time to start of therapy, serum LDH and Calcium levels, anemia and low performance status) (Patil et al, 2011). Conversely, very few papers address the discovery of new biomarkers of treatment efficacy in these patients (Rini et al, 2011).

In the current study, we evaluated the clinical relevance of total and M30-positive CTCs in patients with mRCC during first-line Sunitinib treatment, obtaining new insight about the role and mechanism of CTCs in mRCC and in tumour evasion to antiangiogenic treatment.

Interestingly, $58.5 \% \mathrm{mRCC}$ patients had at least one CTC and $35.8 \%$ patients had two or more CTCs. Considering the low level of EpCAM expression reported in the predominant clear cell histotype RCC, this finding is not assumed. Indeed, by IHC analysis EpCAM positivity was reported in 15 (33\%) of 45 clear cell RCC (Liu et al, 2007), whereas using a dichotomised criteria for positive and negative groups (frequencies of staining of $\geqslant 5 \%$ and $<5 \%$, respectively), in a 318 case series Seligson and coworkers reported that $41 \%$ of clear cell RCC patients were EpCAM-positive (Seligson et al, 2004).

We demonstrated that $41.2 \%$ of mRCC (CC hystotype $81.8 \%$ ) expressed EpCAM in the primary tumour and/or secondary lesions; the great majority of them had CTCs positive, but cells were also detected in cases classified as EpCAM-negative histology. Technical hitches may explain the differing results obtained by IHC and CellSearch analysis. IHC is the most commonly used method for evaluating antigen expression on paraffin-embedded sections of solid tumours. However, this technique depends on the various fixation protocols, assay methods, antibodies, and scoring systems used in different laboratories that altogether limit the value of IHC in measuring antigen expression at single-cell levels. Provided that it uses a robust method, the heterogeneous expression of a given antigen may be potentially more evaluable in tumour cells in peripheral blood.

Nevertheless, we find that the frequency of EpCAM-positive metastasis was higher compared with primary lesions, contrasting previously reported IHC data that metastatic lesions lack EpCAM expression (Went et al, 2005). Limited inter-laboratory IHC reproducibility and tumour heterogeneity may explain our findings, but an alternative intriguing argument is that the enrichment of EpCAM-positive cancer cells may have a role for the invasive phenotype (Maghzal et al, 2010). Indeed, the biological role of EpCAM in carcinogenesis is controversial: loss of membranous EpCAM was reported to contribute to increased migratory potential (Gosens et al, 2007); conversely, abrogating 
A

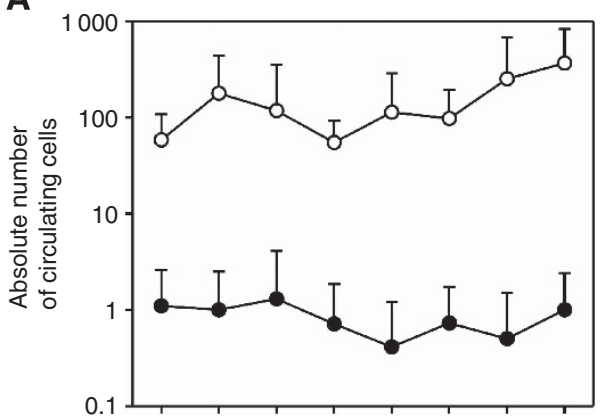

B

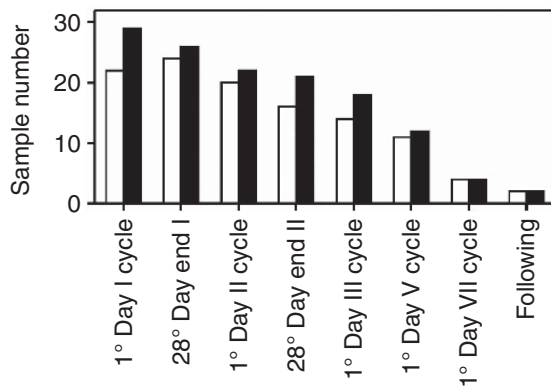

C

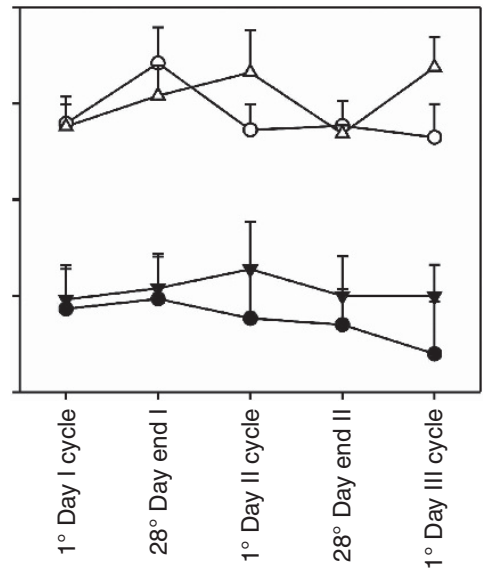

Figure 3 CEC and CTC changes in mRCC patients under Sunitinib. (A) CEC and CTC values (mean + I s.d., white and black symbols, respectively) synchronously determined in $30 \mathrm{mRCC}$ patients receiving Sunitinib treatment are plotted in relation to time. (B) The bars represent the number of CEC and CTC samples (white and black symbols, respectively) collected at each time point. (C) CEC and CTC longitudinal graphs (white and black symbols, respectively) are separately plotted for non-progressed and progressed patients ( $\bigcirc$ and $\nabla$ symbols, respectively). Time points with $n \geqslant 14$ were showed.

E-cadherin-mediated cell-cell adhesion EpCAM expression might promote metastasis (Winter et al, 2003). Moreover, EpCAM overexpression has been associated with both decreased and increased survival of patients (van der Gun et al, 2010). However, EpCAM is also known to be highly expressed in cancer stem cells (Visvader and Lindeman, 2008) in breast, colorectal and pancreatic tumours.

Our study has few limitations that may limit the value of these observations. For example, because of the small cohort of patients, the threshold value of baseline CTCs associated with poor outcome cannot be determined (Cristofanilli et al, 2004), and the prognostic significance of lower than cutoff CTC number cannot be evaluated here. The major finding of the study is provided by the first clear evidence that the amount of live CTCs is a more sensitive marker for rating pharmacodynamic effects compared with total CTCs counts, also when the threshold of poor outcome remains to be defined. The changes in the M30-negative/positive CTCs balance disclose an active disease, as documented by consistent radiological findings, and $\triangle \mathrm{AUC}>0$ (i.e., persistence of live tumour cells under therapy) is associated with progression in individual patient.

We believe that the lack of M30 expression represents in principle a phenotypic (and biologic) property, which should be necessary to metastatic process (Amadori et al, 2009). Furthermore, induction of tumour cell death is regarded as a unique biomarker of treatment efficacy. Hence, through phenotyping CTC for vitality under any treatment and accurately assessing their changes during follow-up it should be possible to stratify CTC on 'biologic' rather than 'statistic' basis, and dichotomise tumour response by the persistence or the lack of live cells.

Sunitinib has been established as a novel standard for first-line therapy, providing a new frontier in the management of metastatic RCC. However, although antitumour effects and survival benefit are often evident, relapse to progressive tumour growth typically ensues, reflecting multiple mechanisms of adaptation to antiangiogenic therapies (Johannsen et al, 2009); indeed, under antiangiogenic pressure distant and accelerated metastasis have been reported in preclinical models (Ebos et al, 2009; Paez-Ribes et al, 2009). In the current study we showed that $64.7 \%$ of the progressed patients relapse with distant metastasis, which were associated with $\triangle A U C>0$ but not with shorter TTP. This finding not only indirectly proves the metastatic potential of the M30-negative CTC, but further underlines the role of antitumour cells targeting for preventing tumour evasion in vivo, as suggested by the observation that positive $\triangle \mathrm{AUC}$ predicts poor outcome better than CEC changes after the first cycle of treatment. Nevertheless, the CTC changes closely mirrored CEC fluctuations measured under the discontinuous schedule of Sunitinib. A rapid increase of the CEC number as fast as the first cycle was associated with CTC decrease in non-progressed patients, whereas a delayed response of CECs was related to higher CTC values in the progressed group, suggesting that the antiendothelial targeting and the antitumour cells effects are strictly linked in vivo.

In conclusion, our data indicate that serial total and apoptotic CTC enumeration in conjunction with standard radiographic imaging improves our ability to accurately assess the treatment benefit for individual mRCC patients under Sunitinib treatment. Prospectively, by gaining more knowledge about mechanisms of tumour adaptation to antiangiogenic treatment the total and apoptotic CTCs enumeration in conjunction with the CEC count might guide the choice of combination or sequences of different agents (including tyrosine kinase inhibitors, mAbs and many more antiangiogenic compounds) for modulating tumour evasion.

\section{ACKNOWLEDGEMENTS}

We thank Ms. Colette Case for editing the manuscript and P Gallo for artwork preparation. The CellSearch platform was sponsored by the association 'IL faro per lo IOV' of the ASCOM Padova. 
This work was supported in part by grants from Banco Popolare di Verona (SI); Alleanza contro il cancro (ACC4; SI); University of Padova, Progetto d'Ateneo 2010 (SI); Regione Veneto (Ricerca sanitaria finalizzata n.11/2008, AA); AIRC (AA).

\section{Conflict of interest}

The authors declare no conflict of interest.

\section{REFERENCES}

Allard WJ, Matera J, Miller MC, Repollet M, Connelly MC, Rao C, Tibbe AG, Uhr JW, Terstappen LW (2004) Tumor cells circulate in the peripheral blood of all major carcinomas but not in healthy subjects or patients with nonmalignant diseases. Clin Cancer Res 10: 6897-6904

Amadori A, Rossi E, Zamarchi R, Carli P, Pastorelli D, Jirillo A (2009) Circulating and disseminated tumor cells in the clinical management of breast cancer patients: unanswered questions. Oncology 76: 375-386

Amadori A, Zamarchi R, De Silvestro G, Forza G, Cavatton G, Danieli GA, Clementi M, Chieco-Bianchi L (1995) Genetic control of the CD4/CD8 T-cell ratio in humans. Nat Med 1: 1279-1283

Bidard FC, Mathiot C, Degeorges A, Etienne-Grimaldi MC, Delva R, Pivot X, Veyret C, Bergougnoux L, de Cremoux P, Milano G, Pierga JY (2010) Clinical value of circulating endothelial cells and circulating tumor cells in metastatic breast cancer patients treated first line with bevacizumab and chemotherapy. Ann Oncol 21: 1765-1771

Blumke K, Bilkenroth U, Schmidt U, Melchior A, Fussel S, Bartel F, Heynemann H, Fornara P, Taubert H, Wirth MP, Meye A (2005) Detection of circulating tumor cells from renal carcinoma patients: experiences of a two-center study. Oncol Rep 14: 895-899

Budd GT, Cristofanilli M, Ellis MJ, Stopeck A, Borden E, Miller MC, Matera J, Repollet M, Doyle GV, Terstappen LW, Hayes DF (2006) Circulating tumor cells versus imaging-predicting overall survival in metastatic breast cancer. Clin Cancer Res 12: 6403-6409

Cristofanilli M, Budd GT, Ellis MJ, Stopeck A, Matera J, Miller MC, Reuben JM, Doyle GV, Allard WJ, Terstappen LW, Hayes DF (2004) Circulating tumor cells, disease progression, and survival in metastatic breast cancer. $N$ Engl J Med 351: 781-791

Danila DC, Heller G, Gignac GA, Gonzalez-Espinoza R, Anand A, Tanaka E, Lilja H, Schwartz L, Larson S, Fleisher M, Scher HI (2007) Circulating tumor cell number and prognosis in progressive castration-resistant prostate cancer. Clin Cancer Res 13: 7053-7058

de Haas EC, di Pietro A, Simpson KL, Meijer C, Suurmeijer AJ, Lancashire LJ, Cummings J, de Jong S, de Vries EG, Dive C, Gietema JA (2008) Clinical evaluation of M30 and M65 ELISA cell death assays as circulating biomarkers in a drug-sensitive tumor, testicular cancer. Neoplasia 10: 1041-1048

Ebos JM, Lee CR, Cruz-Munoz W, Bjarnason GA, Christensen JG, Kerbel RS (2009) Accelerated metastasis after short-term treatment with a potent inhibitor of tumor angiogenesis. Cancer Cell 15: 232-239

Gosens MJ, van Kempen LC, van de Velde CJ, van Krieken JH, Nagtegaal ID (2007) Loss of membranous Ep-CAM in budding colorectal carcinoma cells. Mod Pathol 20: 221-232

Hayes DF, Cristofanilli M, Budd GT, Ellis MJ, Stopeck A, Miller MC, Matera J, Allard WJ, Doyle GV, Terstappen LW (2006) Circulating tumor cells at each follow-up time point during therapy of metastatic breast cancer patients predict progression-free and overall survival. Clin Cancer Res 12: $4218-4224$

Huang D, Ding Y, Li Y, Luo WM, Zhang ZF, Snider J, Vandenbeldt K, Qian CN, Teh BT (2010) Sunitinib acts primarily on tumor endothelium rather than tumor cells to inhibit the growth of renal cell carcinoma. Cancer Res 70: $1053-1062$

Hutson TE, Davis ID, Machiels JP, De Souza PL, Rottey S, Hong BF, Epstein RJ, Baker KL, McCann L, Crofts T, Pandite L, Figlin RA (2010) Efficacy and safety of pazopanib in patients with metastatic renal cell carcinoma. J Clin Oncol 28: 475-480

Johannsen M, Florcken A, Bex A, Roigas J, Cosentino M, Ficarra V, Kloeters C, Rief M, Rogalla P, Miller K, Grunwald V (2009) Can tyrosine kinase inhibitors be discontinued in patients with metastatic renal cell carcinoma and a complete response to treatment? A multicentre, retrospective analysis. Eur Urol 55: 1430-1438

\section{Author contributions}

RZ, ER, SI and UB designed research; RZ, ER, FZ, RC, MF and MB performed research; RZ and AG performed statistical analysis; RZ, ER, SI, AG, UB, AA and MC analyzed and interpreted data; RZ wrote the paper.

Supplementary Information accompanies the paper on British Journal of Cancer website (http://www.nature.com/bjc)

Krishnamurthy S, Cristofanilli M, Singh B, Reuben J, Gao H, Cohen EN, Andreopoulou E, Hall CS, Lodhi A, Jackson S, Lucci A (2010) Detection of minimal residual disease in blood and bone marrow in early stage breast cancer. Cancer 116: 3330-3337

Liu L, Qian J, Singh H, Meiers I, Zhou X, Bostwick DG (2007) Immunohistochemical analysis of chromophobe renal cell carcinoma, renal oncocytoma, and clear cell carcinoma: an optimal and practical panel for differential diagnosis. Arch Pathol Lab Med 131: 1290-1297

Maghzal N, Vogt E, Reintsch W, Fraser JS, Fagotto F (2010) The tumorassociated EpCAM regulates morphogenetic movements through intracellular signaling. J Cell Biol 191: 645-659

Marshall FF, Dietrick DD, Baumgartner WA, Reitz BA (1988) Surgical management of renal cell carcinoma with intracaval neoplastic extension above the hepatic veins. J Urol 139: 1166-1172

McDermott DF, Regan MM, Clark JI, Flaherty LE, Weiss GR, Logan TF, Kirkwood JM, Gordon MS, Sosman JA, Ernstoff MS, Tretter CP, Urba WJ, Smith JW, Margolin KA, Mier JW, Gollob JA, Dutcher JP, Atkins MB (2005) Randomized phase III trial of high-dose interleukin-2 versus subcutaneous interleukin-2 and interferon in patients with metastatic renal cell carcinoma. J Clin Oncol 23: 133-141

McShane LM, Altman DG, Sauerbrei W, Taube SE, Gion M, Clark GM (2005) Reporting recommendations for tumor marker prognostic studies (REMARK). J Natl Cancer Inst 97: 1180-1184

Motzer RJ, Hutson TE, Tomczak P, Michaelson MD, Bukowski RM, Rixe O, Oudard S, Negrier S, Szczylik C, Kim ST, Chen I, Bycott PW, Baum CM, Figlin RA (2007) Sunitinib versus interferon alfa in metastatic renal-cell carcinoma. N Engl J Med 356: 115-124

Paez-Ribes M, Allen E, Hudock J, Takeda T, Okuyama H, Vinals F, Inoue M, Bergers G, Hanahan D, Casanovas O (2009) Antiangiogenic therapy elicits malignant progression of tumors to increased local invasion and distant metastasis. Cancer Cell 15: 220-231

Patil S, Figlin RA, Hutson TE, Michaelson MD, Negrier S, Kim ST, Huang X, Motzer RJ (2011) Prognostic factors for progression-free and overall survival with sunitinib targeted therapy and with cytokine as first-line therapy in patients with metastatic renal cell carcinoma. Ann Oncol 22: 295-300

Pierga JY, Hajage D, Bachelot T, Delaloge S, Brain E, Campone M, Dieras V, Rolland E, Mignot L, Mathiot C, Bidard FC (2012) High independent prognostic and predictive value of circulating tumor cells compared with serum tumor markers in a large prospective trial in first-line chemotherapy for metastatic breast cancer patients. Ann Oncol 23: 618-624

Ratain MJ, Eisen T, Stadler WM, Flaherty KT, Kaye SB, Rosner GL, Gore M, Desai AA, Patnaik A, Xiong HQ, Rowinsky E, Abbruzzese JL, Xia C, Simantov R, Schwartz B, O’Dwyer PJ (2006) Phase II placebo-controlled randomized discontinuation trial of sorafenib in patients with metastatic renal cell carcinoma. J Clin Oncol 24: 2505-2512

Riethdorf S, Fritsche H, Muller V, Rau T, Schindlbeck C, Rack B, Janni W, Coith C, Beck K, Janicke F, Jackson S, Gornet T, Cristofanilli M, Pantel K (2007) Detection of circulating tumor cells in peripheral blood of patients with metastatic breast cancer: a validation study of the CellSearch system. Clin Cancer Res 13: 920-928

Rini BI, Cohen DP, Lu DR, Chen I, Hariharan S, Gore ME, Figlin RA, Baum MS, Motzer RJ (2011) Hypertension as a biomarker of efficacy in patients with metastatic renal cell carcinoma treated with sunitinib. J Natl Cancer Inst 103: 763-773

Rossi E, Basso U, Celadin R, Zilio F, Pucciarelli S, Aieta M, Barile C, Sava T, Bonciarelli G, Tumolo S, Ghiotto C, Magro C, Jirillo A, Indraccolo S, Amadori A, Zamarchi R (2010) M30 neoepitope expression in epithelial cancer: quantification of apoptosis in circulating tumor cells by CellSearch analysis. Clin Cancer Res 16: 5233-5243 
Rowand JL, Martin G, Doyle GV, Miller MC, Pierce MS, Connelly MC, Rao C, Terstappen LW (2007) Endothelial cells in peripheral blood of healthy subjects and patients with metastatic carcinomas. Cytometry A 71: 105-113

Sandri MT, Zorzino L, Cassatella MC, Bassi F, Luini A, Casadio C, Botteri E, Rotmensz N, Adamoli L, Nole F (2010) Changes in circulating tumor cell detection in patients with localized breast cancer before and after surgery. Ann Surg Oncol 17: 1539-1545

Sastre J, Maestro ML, Puente J, Veganzones S, Alfonso R, Rafael S, GarciaSaenz JA, Vidaurreta M, Martin M, Arroyo M, Sanz-Casla MT, DiazRubio E (2008) Circulating tumor cells in colorectal cancer: correlation with clinical and pathological variables. Ann Oncol 19: 935-938

Seligson DB, Pantuck AJ, Liu X, Huang Y, Horvath S, Bui MH, Han KR, Correa AJ, Eeva M, Tze S, Belldegrun AS, Figlin RA (2004) Epithelial cell adhesion molecule (KSA) expression: pathobiology and its role as an independent predictor of survival in renal cell carcinoma. Clin Cancer Res 10: 2659-2669 van der Gun BT, Melchers LJ, Ruiters MH, de Leij LF, McLaughlin PM, Rots MG (2010) EpCAM in carcinogenesis: the good, the bad or the ugly. Carcinogenesis 31: 1913-1921

Visvader JE, Lindeman GJ (2008) Cancer stem cells in solid tumours: accumulating evidence and unresolved questions. Nat Rev Cancer 8: 755-768

Went P, Dirnhofer S, Salvisberg T, Amin MB, Lim SD, Diener PA, Moch H (2005) Expression of epithelial cell adhesion molecule (EpCam) in renal epithelial tumors. Am J Surg Pathol 29: 83-88

Winter MJ, Nagelkerken B, Mertens AE, Rees-Bakker HA, Briaire-de Bruijn IH, Litvinov SV (2003) Expression of Ep-CAM shifts the state of cadherin-mediated adhesions from strong to weak. Exp Cell Res 285: $50-58$

Xin H, Zhang C, Herrmann A, Du Y, Figlin R, Yu H (2009) Sunitinib inhibition of Stat3 induces renal cell carcinoma tumor cell apoptosis and reduces immunosuppressive cells. Cancer Res 69: 2506-2513

This work is published under the standard license to publish agreement. After 12 months the work will become freely available and the license terms will switch to a Creative Commons Attribution-NonCommercial-Share Alike 3.0 Unported License. 